\title{
Targeting different types of human meningioma and glioma cells using a novel adenoviral vector expressing GFP-TRAIL fusion protein from hTERT promoter
}

Jessica T Li ${ }^{1,3}$, Ka Bian ${ }^{5}$, Alan L Zhang ${ }^{2}$, Dong H Kim¹, William W Ashley ${ }^{1}$, Rahul Nath', lan McCutcheon², Bingliang Fang ${ }^{2^{*}}$ and Ferid Murad ${ }^{5^{*}}$

\begin{abstract}
Objective: The objective of this study was to evaluate the anti-tumor effects of Ad/gTRAIL (an adenoviral vector in which expression of GFP and TRAIL is driven by a human telomerase reverse transcriptase promoter, hTERT) on malignant meningiomas and gliomas.

Background: Gliomas and meningiomas are the two most common types of human brain tumors. Currently there is no effective cure for recurrent malignant meningiomas or for gliomas. Ad/gTRAlL has been shown to be effective in killing selected lung, colon and breast cancer cells, but there have been no studies reporting its antitumor effects on malignant meningiomas. Therefore, we tested the antitumor effect of Ad/gTRAlL for the first time in human malignant meningioma and glioma cell lines, and in intracranial M6 and U87 xenografts.

Methods: Materials and Methods: Human malignant meningioma and glioma cells were infected with adenoviruses, Ad/gTRAIL and Ad/CMV-GFP. Cell viability was determined by proliferation assay. FACS analysis and quantification of TRAIL were used to measure apoptosis in these cells. We injected Ad/gTRAIL viruses in intracranial M6 and U87 xenografts, and measured the brain tumor volume, quantified apoptosis by TUNEL assay in the brain tumor tissue.

Results: Our studies demonstrate that in vitro/in vivo treatment with Ad/gTRAlL virus resulted in significant increase of TRAIL activity, and elicited a greater tumor cell apoptosis in malignant brain tumor cells as compared to treatment with the control, Ad/CMV-GFP virus without TRAIL activity.
\end{abstract}

Conclusions: We showed for the first time that adenovirus Ad/gTRAlL had significant antitumor effects against high grade malignant meningiomas as well as gliomas. Although more work needs to be done, our data suggests that Ad/gTRAlL has the potential to be useful as a tool against malignant brain tumors.

\section{Background}

Gliomas and meningiomas are the two most common types of human brain tumors. Malignant gliomas are the most aggressive and deadliest type of brain tumor[1]. Meningiomas, on the other hand, are usually benign but often recur after surgical removal. They can undergo

\footnotetext{
* Correspondence: bfang@mdanderson.org; FeridMurad@Gmail.com ${ }^{2}$ Department of Thoracic and Cardiovascular Surgery, The University of Texas M. D. Anderson Cancer Center, Houston, Texas 77030, USA

${ }^{5}$ Department of Biochemistry and Molecular Biology, The George Washington University Medical Center, 2300 I Street, NW, Washington, DC 20037, USA

Full list of author information is available at the end of the article
}

malignant transformation, and depending on their location can be serious and even potentially lethal to patients [2]. It has been reported that there has been a steady increase in the incidence of malignant brain tumors in both adults and children [3]. There is no effective longterm treatment for this disease. Cellular and molecular therapies including novel vector based gene therapy are currently being studied in preclinical and clinical settings for intracranial malignancies [4-6].

Telomerase is the cellular enzyme responsible for the replication of chromosomal ends or telomeres. It is a multiunit ribonucleoprotein complex that contains an 
essential RNA component, human telomerase RNA (hTR) and essential protein components including the rate-limiting catalytic subunit human telomerase reverse transcriptase (hTERT). The strong link between telomerase activity and cancer was initially reported by Kim et al [7]. Using a highly sensitive PCR based telemetric repeat amplification protocol (TRAP) assay, they detected telomerase activity in many advanced tumors but not in normal somatic tissues or benign tumors. Since then, all major types of cancer have been screened for telomerase activity. It has been estimated that more than $85 \%$ of human cancers have high telomerase activity, which makes telomerase the most common tumor marker. Not only has telomerase been proposed as a diagnostic and prognostic marker for cancer, telomerase inhibition has been widely tested as a potential anticancer strategy [8]. In addition, the high tumor-specificity of hTERT gene expression and the fact that hTERT expression is mainly regulated at the transcriptional level have prompted the use of an hTERT promoter to drive suicide genes to induce specific cancer cell killing using liposome or adenovirus delivery systems [9].

TRAIL, a member of the TNF family, triggers apoptosis through interactions with death receptors (DR4 and DR5) on the cell surface. We and others have shown that direct transfer of the full-length coding sequence of the human tumor necrosis factor-related apoptosis-inducing ligand (TRAIL) into cancer cells elicited apoptosis and apoptotic bystander effects on malignant cells and suppressed tumor growth in vivo. More recently, we constructed a bicistronic adenoviral vector expressing the GFP-TRAIL fusion protein from the hTERT promoter via GAL4 gene regulatory system (Ad/gTRAIL) and demonstrated that Ad/gTRAIL treatment effectively elicited apoptosis in various tumor cells in vitro and suppressed xenograft tumor growth in vivo, with no detectable toxicity in human primary hepatocytes [10]. Since the hTERT promoter is tumor specific, expressing the TRAIL gene by hTERT could overcome the possible liver toxicity reported for TRAIL gene expression.

In this report, we determined the expression level of hTERT in benign and malignant meningioma and glioma cells and investigated the expression and efficacy of Ad/ gTRAIL in these cells. Our data showed that Ad/gTRAIL is effective against highly malignant meningioma and gliomas without toxicity to normal cells in the brain and suggest that Ad/gTRAIL may have potential usage in malignant brain tumor therapy.

\section{Results and Discussion}

\section{hTERT expression level in primary cultured meninglioma} cells and glioma cell lines

In general, hTERT expression levels correlate with the degree of malignancy in cancer cells. We evaluated the
hTERT mRNA expression in primary cultured meningioma cells and glioma cell lines using real-time RT Q-PCR technique. As shown in (Figure 1A), very low levels of hTERT expression were detected in three benign meningioma cells (M43, M2, and M66) while higher level hTERT was noted in M6 malignant meningioma cells. All 3 higher grade glioma cell lines (U251, U87, and U373) had significantly elevated hTERT expression. However, NG-1 cells, derived from surgical specimens of human gliomas (established in the Department of NeuroOncology at The University of Texas M. D. Anderson Cancer Center) showed a lower expression of hTERT [11]. The low grade SW1088 glioma cell line also demonstrated decreased hTERT levels [12]. These results confirmed that hTERT mRNA expression correlates with the malignancy level of brain tumor cells.

\section{Correlation between GFP-TRAIL expression and hTERT level}

hTERT is over expressed in up to $90 \%$ of cancer cells $[13,14]$. Moreover, Ad/gTRAIL has been shown to be selectively active in cancer cells. To test the effect of Ad/ gTRAIL on malignant brain tumors, we treated meningioma cells (benign: M43, M2, M66; malignant: M6) and glioma cells (NG-1, SW1088, U251, U87) with Ad/ gTRAIL or Ad/CMV-GFP. Cells treated with PBS were used as a control. Cells were harvested $48 \mathrm{hr}$ after virus treatment, and then divided into two parts. One part was used for GFP expression detection, and another part was used for apoptosis analysis. As shown in (Figure 2A), benign meningioma cells (M43, M2, M66) treated with Ad/gTRAIL resulted in similar lower levels of GFP-positive cells $(7.94 \%, 12.65 \%$ and $6.25 \%$ respectively), suggesting that hTERT promoter activity was minimal in these cells. On the other hand, Ad/gTRAIL infected M6 malignant meningioma cells demonstrated significantly higher GFP-positive cells (82.08\%), reflecting increased hTERT promoter activity. Similarly, the two highly malignant glioma cell lines (U251 and U87) also had a high percentage of GFP-positive cells ( $73.1 \%$ and $84.5 \%$ respectively), indicating high hTERT promoter activity (Figure $2 \mathrm{~B}$ ). The cells lines with intermediate hTERT expression (NG-1 and SW1088) showed $36.4 \%$ and $47.4 \%$ GFP-positive cells respectively (Figure 2B). Cells with PBS treatment have no significant GFP-positive cells detected. There was no significant difference in GFP-positive cells among different group of cells treated with control vector Ad/CMV-GFP.

\section{Targeting TRAIL induced apoptosis in malignant cells by Ad/gTRAIL}

Treatment of benign meningioma cells (M43, M2, M66) with Ad/gTRAIL did not change the apoptosis rate when compared to cells treated with control vector Ad/CMVGFP, indicating lack of hTERT-targeted mechanism. 
A

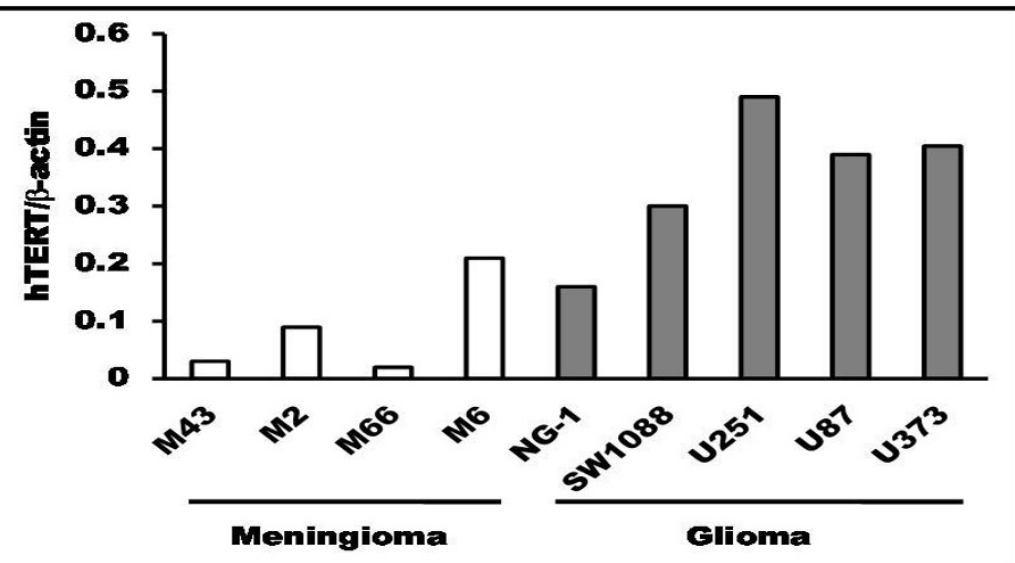

B-1
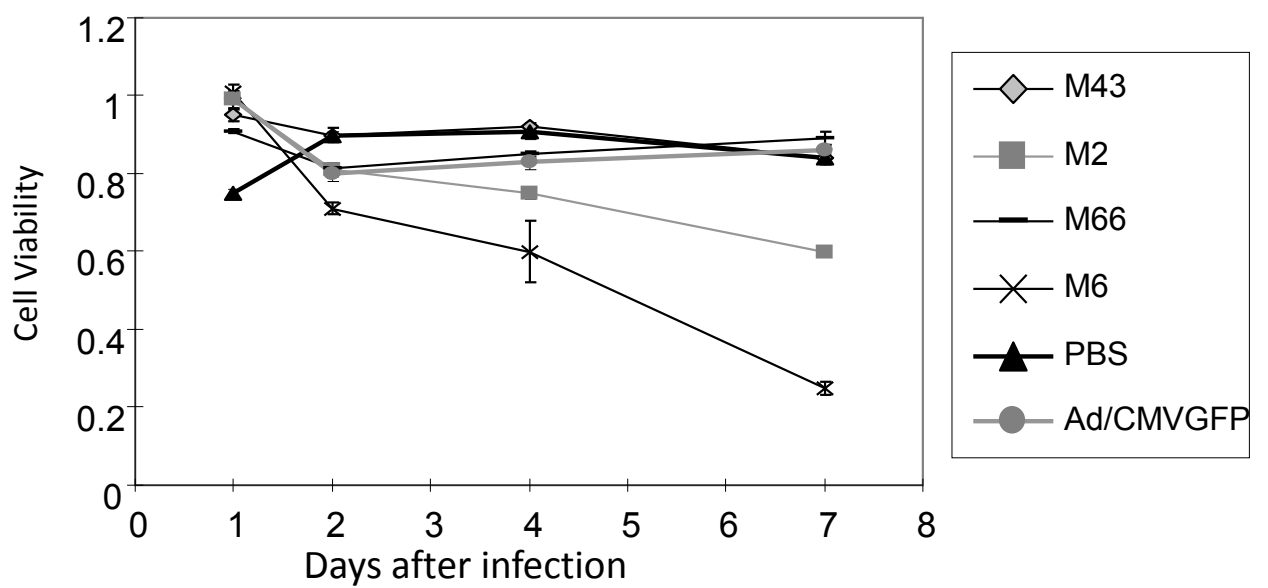

B-2
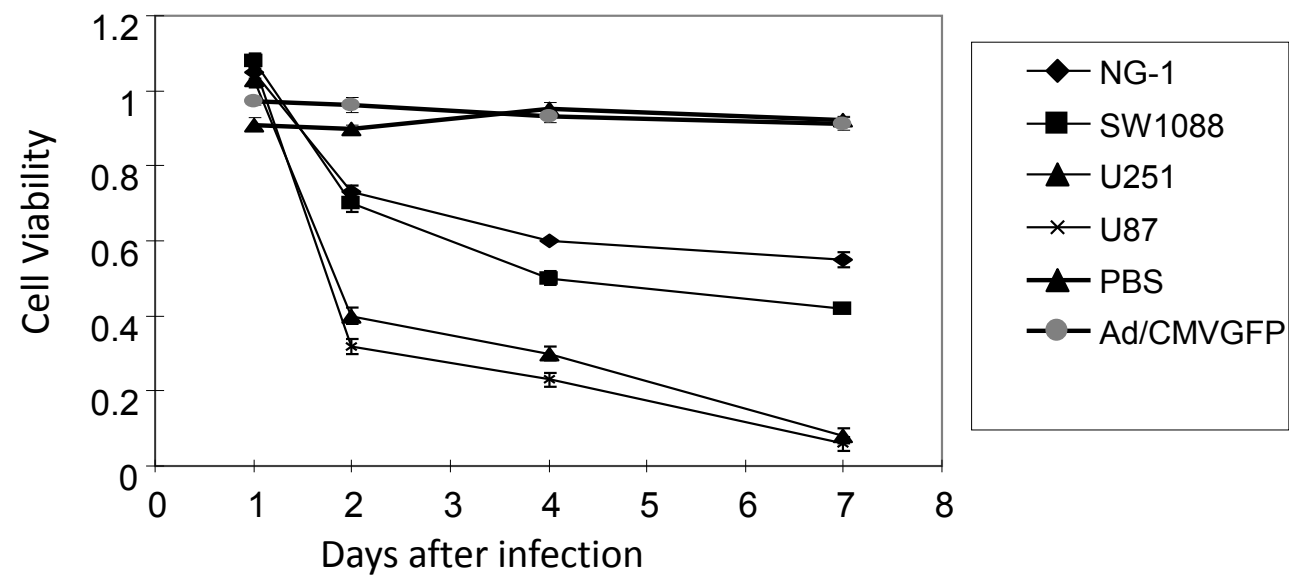

Figure 1 Endogenous hTERT activity and cell killing effect of Ad/gTRAIL: (A) Endogenous hTERT mRNA level in meningioma and glioma cells. The hTERT mRNA level in primary cultured meningioma cells and glioma cell lines was determined by real time quantitative PCR as described the Methods. The levels of $\beta$-actin was used as endogenous controls. (B) In vitro cell-killing effect of Ad/TRAlL on various brain tumor cells. (B-1) Meningioma cells (B-2) Glioma cells. Cell viability was determined by XTT assay. Cells treated with PBS were used as a control, and their viability was set at 1. Values are mean \pm SD for two quadruplicate assays PBS (mock control), Ad/CMV-GFP (vector control), and M43, M2, M66, M6 and NG-1 SW1088, U251, U87, Ad/gTRAlL., Cells were treated with MOI of 1000 VPs/ cell at 7 consecutive days. Cell viabiligy of M6, U251, and U87 cells treated with Ad/gTRAlL was significantly different $(p<0.001)$ from that of Ad/CMV-GFP and PBS treated cells. 


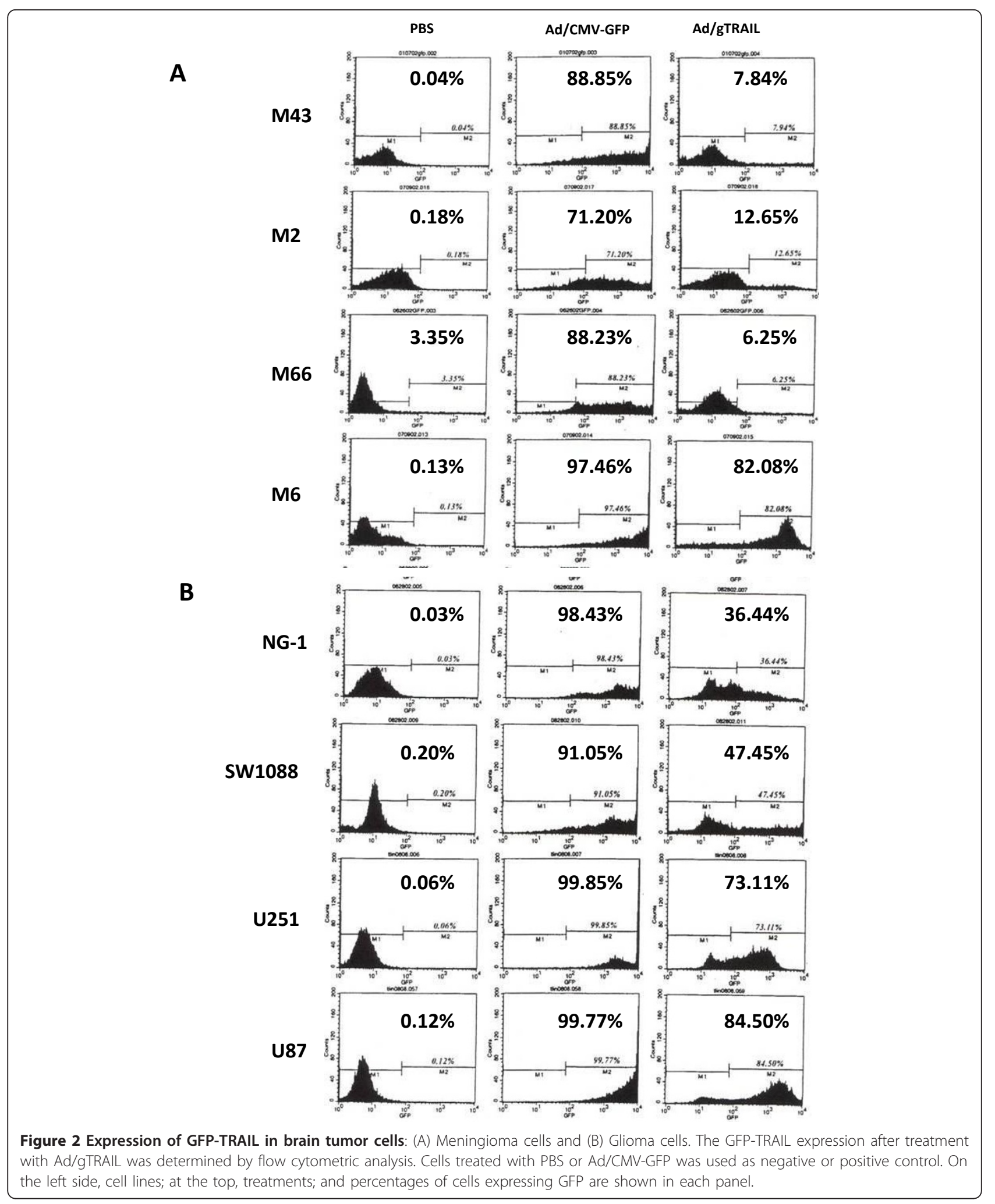


However, malignant meningioma M6 cells treated with Ad/gTRAIL showed 24\% apoptosis rate, which is 4-fold higher than cells treated with control Ad/CMV-GFP (Figure 3A). In addition, Ad/gTRAIL induced significant apoptosis (58\% and $30.6 \%$ ) in highly malignant U251 and U87 cells respectively (Figure $3 \mathrm{~B}$ ). The percentages of apoptosis for intermediate level hTERT expressing cell lines are: NG-1, 13.9\% and SW1088, 18.4\% (Figure 3B). Cells with PBS treatment have no effect on apoptosis induction. It is noteworthy that control vector Ad/CMVGFP did not induce additional apoptosis as to PBS treated groups.

\section{Cytopathic effect of Ad/gTRAIL on human brain tumor cells}

To determine whether the infection of human brain tumor cells with either Ad/gTRAIL or Ad/CMV-GFP would have a cytopathic effect, we performed dose-dependence assays with low-hTERT benign meningioma M66 cell, and highhTERT glioma U87 cell. The cells were seeded at $1 \times 10^{4}$ cells/well in flat-bottom 12-well plates. After an overnight incubation, cells were divided into 3 groups and treated with PBS, Ad/CMV-GFP, Ad/g-TRAIL respectively. The treatment concentration of Ad/CMV-GFP, Ad/g TRAIL were at MOIs of 500, 1000 and $3000 \mathrm{VPs} /$ cell. Benign meningioma cells were evenly infected by the control vector Ad/CMV-GFP, showing strong green fluorescence (Figure 4A).

However, due to selective expression of GFP-TRAI, green fluorescence was observed only in malignant cells (Figure 4F), and not in benign cells, (Figure 4B). This suggests that after Adv/g TRAIL infection, differential expression of the adenoviral transgene is mediated by the tumor-selective promoter system and not influenced by cellular susceptibility to virus infection. As shown in (Figure 4C \& 4D), no obvious morphologic changes were observed up to 5 days after all the treatments, suggesting that even at an MOI of $3000 \mathrm{VPs} /$ cell, Ad/gTRAIL is not toxic to, and has no cytopathic effect on benign meningioma cells. In comparison, obvious apoptotic morphologic changes were observed in the maligant glioma cells after treatment with Ad/gTRAIL at an MOI of $1000 \mathrm{VPs} /$ cell (Figure 4F \&4H). This result was consistent with our previous observation that transgene expression from the hTERT promoter after adenovector-mediated gene delivery is high in malignant cells but minimal in normal cells $[10,15]$. This result also demonstrated that hTERT promoter activity was in different levels in different grade brain tumor cells.

\section{Anti-proliferation effect of Ad/gTRAIL on human brain tumor cells}

To obtain further evidence that the hTERT promoter can drive tumor specific expression of the TRAIL gene in different grade menigioma and glioma cells, we used the XTT assay to compare cell viability after treatment with Ad/gTRAIL in all meningioma (Figure 1.B-1) and glioma cells (Figure 1.B-2). The cell viability was significantly lower in Ad/gTRAIL treatedU251, U87-glioma cells ( $\mathrm{p}<$ $0.001)$, and M6 malignant meningioma cells $(\mathrm{p}<0.001)$ when compared to the control Ad/CMV-GFP and PBS treated. The increased cell death in U87 and U251 glioma, and M6 malignant meningioma cells was directly correlated with hTERT expression level (Figure 3).

\section{Apoptosis pathway elicited by Ad/gTRAIL in human brain tumor cells}

The induction of apoptosis by Ad/gTRAIL was confirmed by western blot analysis (Figure 5). The TRAIL expression was observed in cells treated with1000 MOI Ad/CMVGFP at 3 days (A),. and treated with $1000 \mathrm{MOI}$ Ad/gTRAI at 3 days (B). However, there was an increased expression of TRAIL in meninglioma M6 and glioma U251 and U87 cells treated with Ad/gTRAIL when compared to benign cells. Additionally, our data demonstrated that Ad/ gTRAIL was more effective in causing cell death and apoptosis induction in malignant human brain tumor cells, but not in benign tumor cells. This result suggests that apoptosis is involved in cell death produced by the TRAIL gene therapy.

\section{Therapeutic effect of Ad/gTRAIL in intracranial xenografted M6 and U87}

To evaluate the therapeutic effect of Ad/gTRAIL in brain tumors in vivo, we measured the anti-tumor growth efficacy of Ad/gTRAIL in intracranial xenografted M6 meningioma and U87 glioma, and compared it with that of control vector Ad/CMV-GFP, and. In four independent experiments, the mean survival for the control mice (mice receiving Ad/CMV-GFP) was 19 days (95\% CI = 14 to 24 ) in meningioma, and 22 days ( $95 \% \mathrm{CI}=15$ to 30 days) in glioma respectively. In contrast, the survival for the $\mathrm{Ad} /$ gTRAIL treated mice was 61 days $(95 \% \mathrm{CI}=50$ to 69 days) in meningioma, and 63 days $(95 \% \mathrm{CI}=52$ to 71 days) in glioma which was statistically significantly longer than the mean survival of the control mice $(\mathrm{p}<0,05$; logrank test), (Figure 6A).

\section{Histopatholgic Examination of Tumor in Brain}

Microscopic examination of the brain of control mice with M6 meningioma xenografts revealed non-infiltrative tumor growing in a spherical pattern (Figure 6B1). Histological characteristics of the tumors included a dense cellular mass, and the tumor center had necrotic areas (Figure 6-B2 Arrow). All the brains of M6 and U-87 xenografted mice that died naturally showed a midline shift and ventricular compression secondary to tumor-mass effects, which are characteristic features of herniation, and 


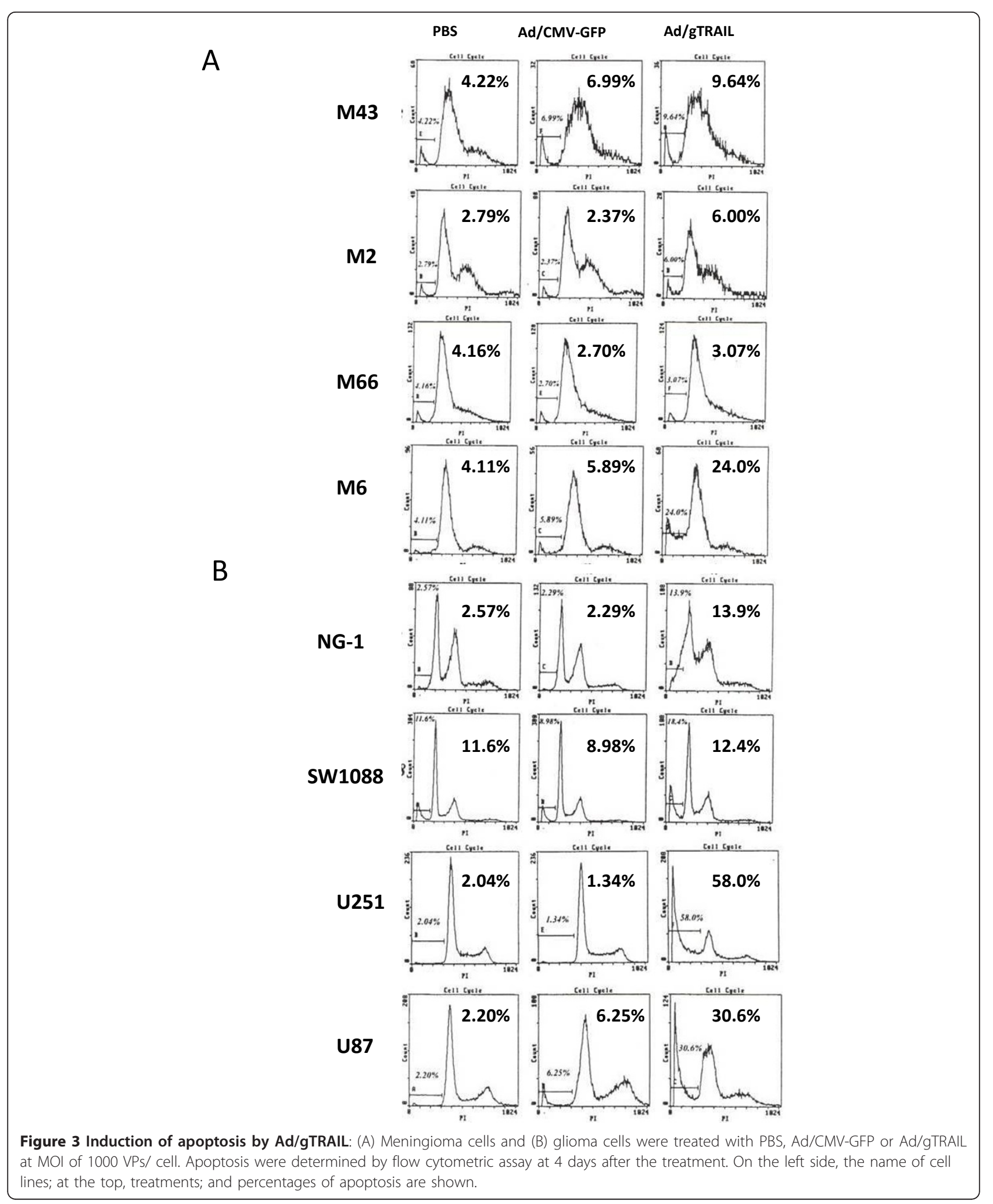




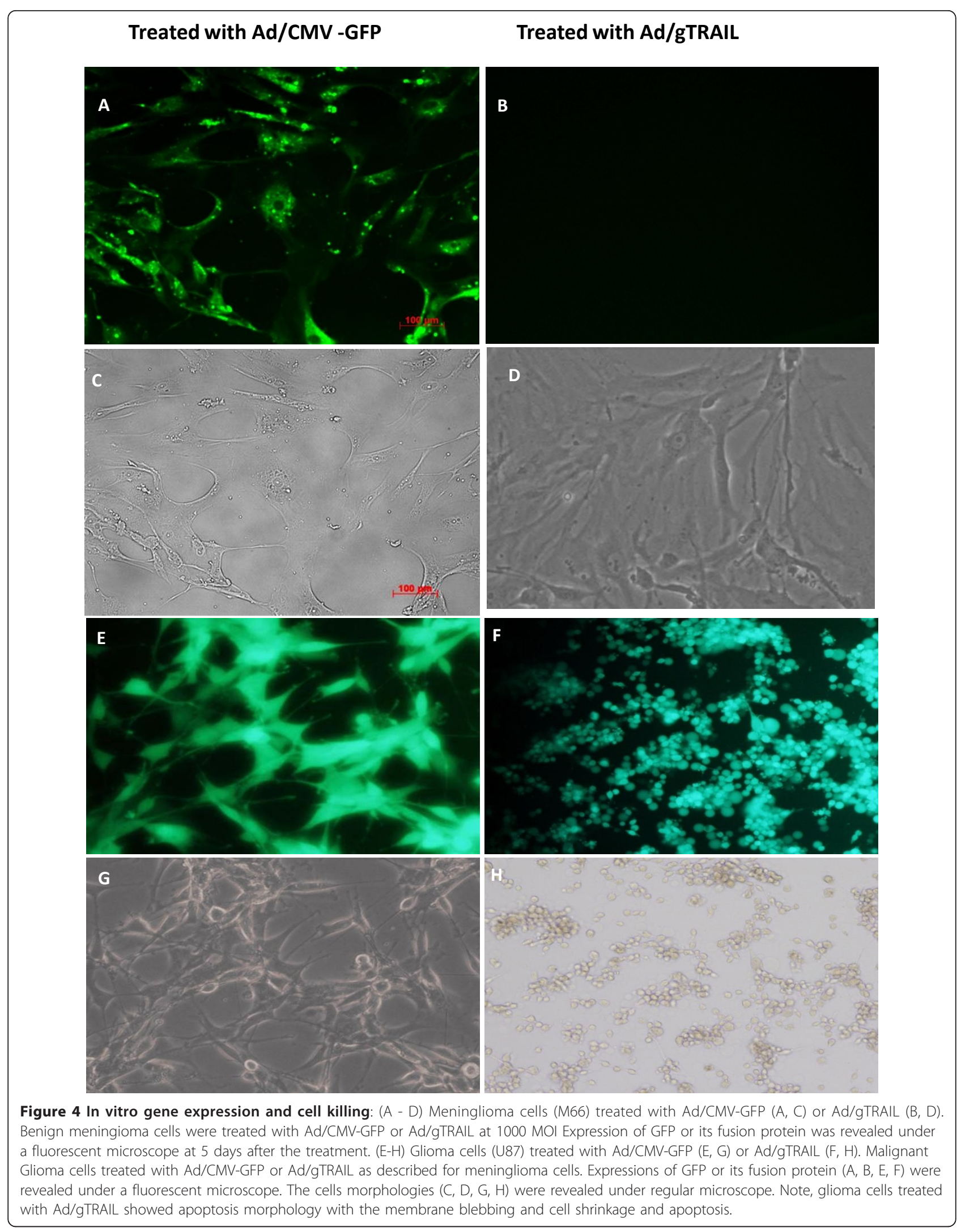




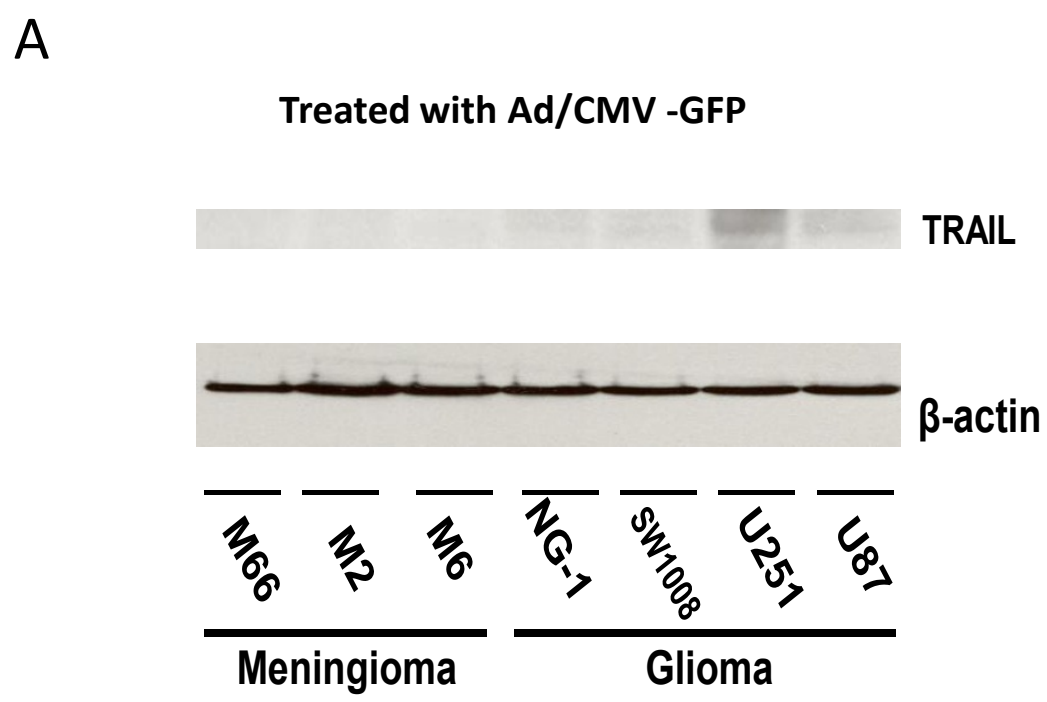

Treated with Ad/gTRAIL

B

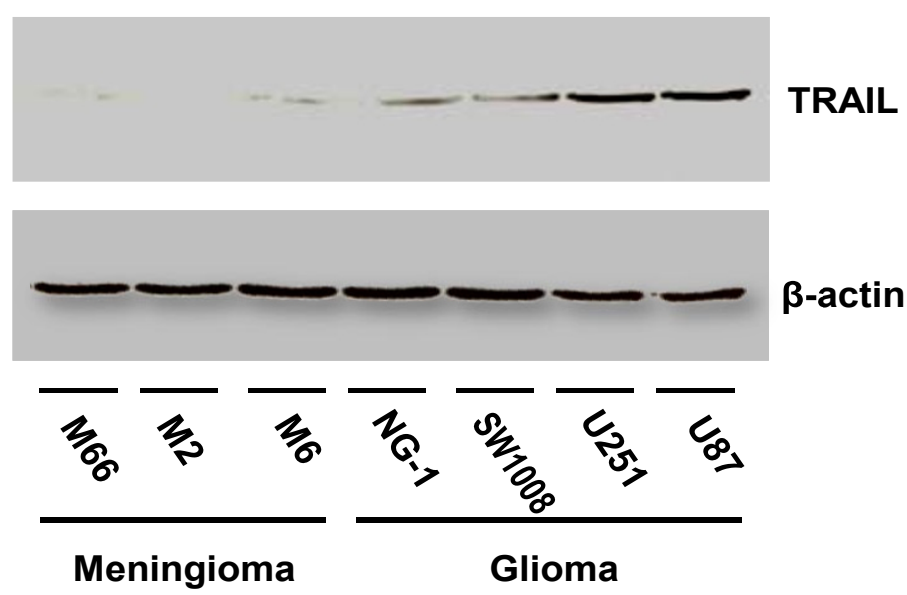

Figure 5 The TRAIL gene expression in brain tumor cells: (A) Cells were treated with Ad/CMV-GFP at 1000 MOI VPs/ cell at 3 days. (B) Cells were treated with Ad/gTRAIL at $1000 \mathrm{MOI}$ VPs/ cell at 3 days. Protein levels were analyzed by Western blot analysis after the treatment. $\beta$-actin was used as loading control.

indicate that growth was probably the cause of death in mice that died naturally.

\section{Immunohistochemical staining for TUNEL assay}

To assess apoptosis induction in vivo, we performed terminal deoxynucleotidyl transferase-mediated dUTP labeling (TUNEL) staining on tumor sections in 2 treatment groups. Brown color indicates apoptotic nuclei as visualized using the DAB substrate. Apoptosis was calculated as percentage of at least 1000 second cells. As shown in (Figure 7 ), treatment Ad/gTRAIL in meninglioma resulted in significantly higher apoptotic $63.2 \%(\mathrm{C})$, when compared to control Ad/CMV-GFP 4.4\% (A). In glioma, treatment Ad/ gTRAIL resulted in higher apoptotic index $68.9 \%$ (D), compared to Ad/CMV-GFP 5.2\% (B). Result of in situ TUNEL staining in tumor meningioma and glioma section. 
A

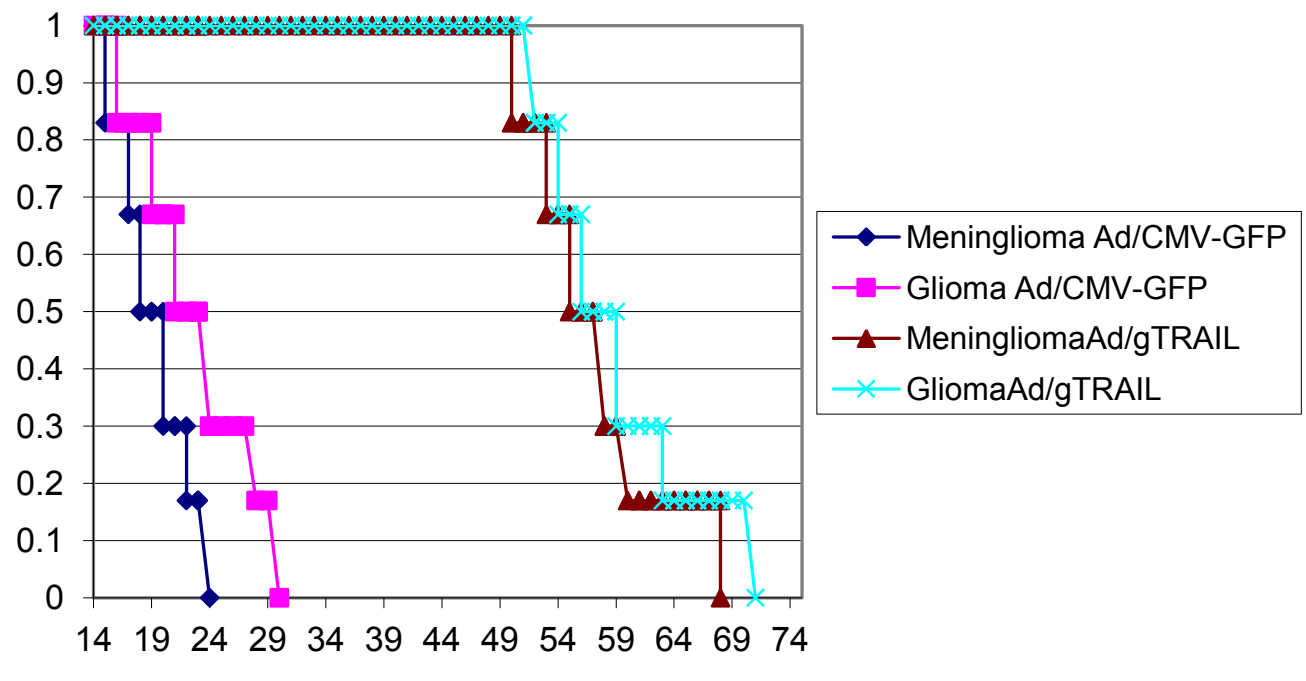

B
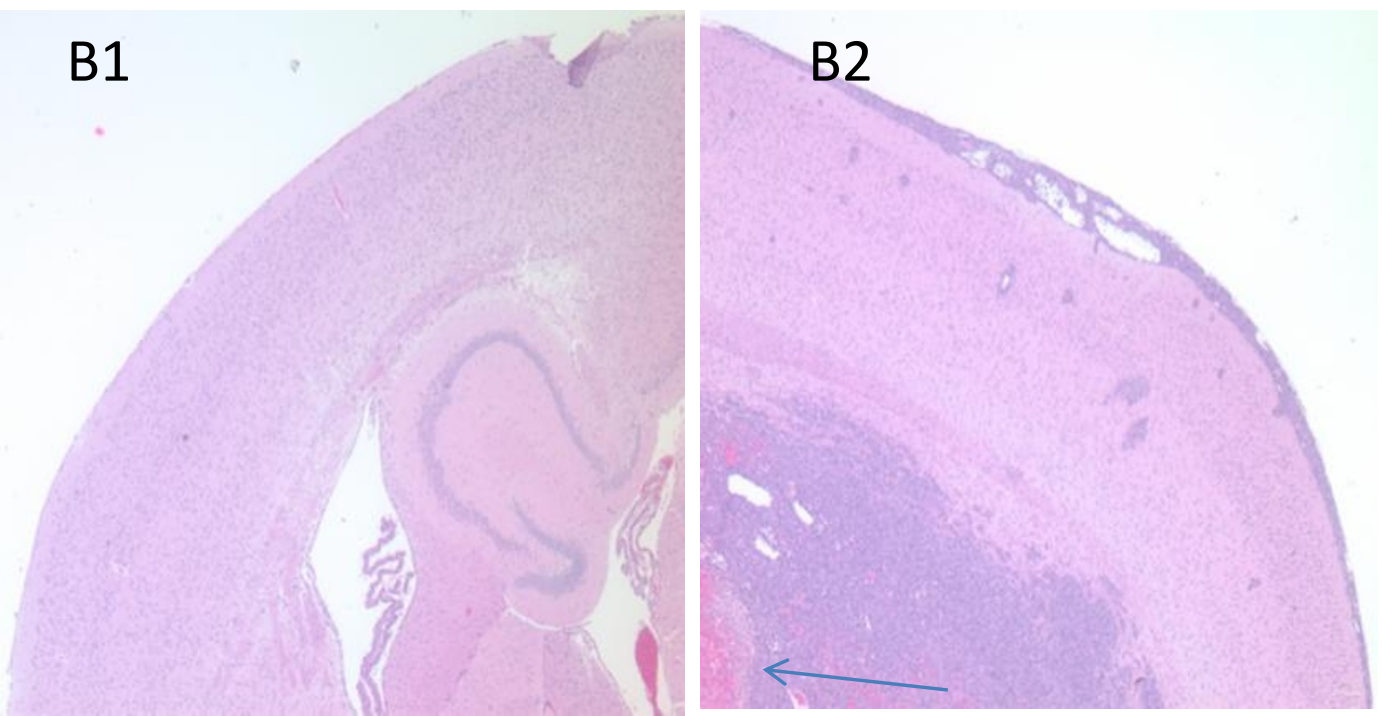

Figure 6 In vivo antitumor activity of Ad/gTRAIL: (A) Survival of animals treated with Ad/gTRAlL. Nude mice bearing intracranial M6 and U-87 xenografts were injected intratumorally with Ad/CMV-GFP or Ad/gTRAlL at doses of $1.5 \times 10^{8}$ viral particles in $5 \mu \mathrm{L}$ for 3 days. The Kaplan-Meier survival curve for each group was shown in the paragraph ( $n=6$ animals in each group). The mean survival for the control mice Ad/CMV-GFP) was 19 days in M6 and 26 days in U87 respectively. In contrast, the survival for the Ad/gTRAlL treated mice was 61 days in M6 and 63 days in U87, which was statistically significantly longer than the mean survival of control mice $(p<0.05)$. (B) The athymic mice brain section (B1) with Meninglioma xenograft (B2). 


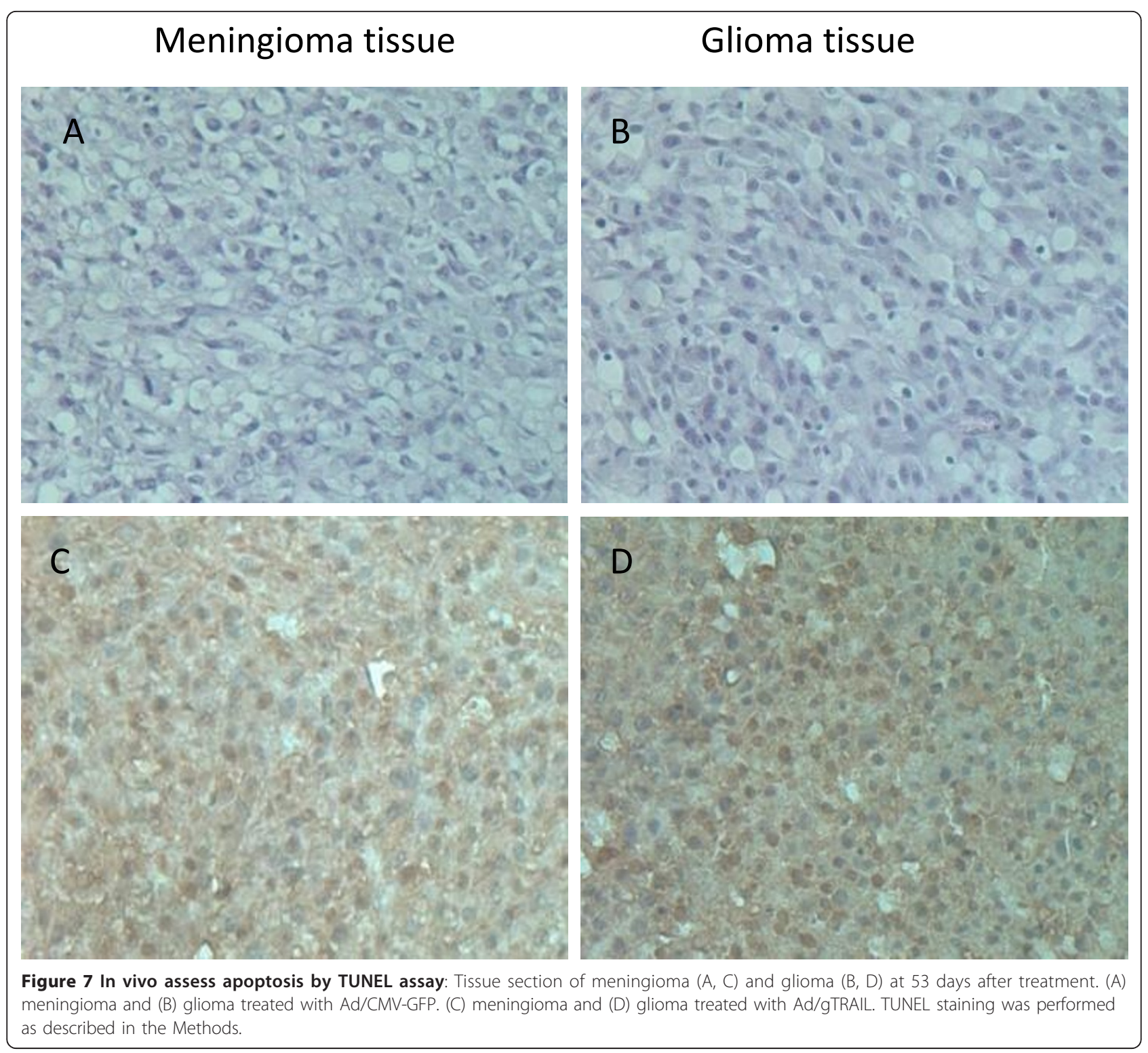

\section{Conclusions}

The tumor necrosis factor related apoptosis-inducing ligand (TRAIL) has received a great attention in cancer treatment because it induces apoptosis in cancer cells but not in normal cells. TRAIL belongs to a small subset of proapoptotic protein ligands in the TNF superfamily $[16,17]$, which triggers apoptosis through interactions with death/TRAIL receptors (DR4/TRAIL-R1 and DR5/ TRAIL-R2)[18], and activation of caspase-8 at the deathinducing signaling complex (DISC) on the cell surface [19]. TRAIL-receptor agonists are considered as promising cancer therapeutics, and are currently under evaluation in early clinical trials[20]. Recombinant human Apo2L/TRAIL (rhApo2L/TRAIL), a dual proapoptotic receptor agonist has been successfully studied in patients with advanced cancer in clinical trial for cancer therapy $[20,21]$.

Our previous study showed that expression of TRAIL in cancer cells induced apoptosis and bystander effect and that the bystander effect required cell-cell contact antitumor activity [22,23]. Required cell to cell contact suggests that interaction of membrane TRAIL with its receptors (DR5 or DR4) in neighboring cells is an important mechanism of the TRAIL induced cell death. However, it remains unclear whether endogenous expression of TRAIL itself will be sufficient to induce cell death. In this study, we compared Ad/gTRAIL induced cell death in relative confluent cells and in very diluted cultured cells where cell-cell contact was minimal. Our result showed that treatment with Ad/gTRAIL virus elicited 
similar levels of apoptosis in the confluent and diluted cells, suggesting that endogenous expression of TRAIL itself is sufficient to induce cell death in the sensitive cancer cells (data not shown).

Control of gene expression via tissue-or cell-specific promoters is a means of targeting transgene expression. Tumor-specific promoters have the potential to selectively destroy cancer cells while sparing normal cells. We previously showed that hTERT promoter is highly active in most cancer cells but not in normal cells and normal mouse tissues, and can be used for targeting of the therapeutic effects of a proapoptotic gene using adenoviral vector mediated gene delivery $[12,24]$. Nevertheless, comparing with a strong constitutive promoter such as CMV promoter, the activity of hTERT is relatively weak. Therefore, Ad/gTRAIL used bicistron expression system to augment the hTERT promoter activity in cancer cells. In this bicistron system, hTERT promoter is used to drive the expression of GAL4/VP16 which in turn activates its target promoter consisting of GAL4 binding sites and TATA box (GT)[25]. Targeted expression of green Antitumor activity leading to augmented transgene expression. Our previous study showed this system could augment transgene expression from the CEA or hTERT promoter up to 100 fold, whether in vitro or in vivo without loss of its specificity $[26,27]$.

Recombinant TRAIL proteins could elicit anticancer activity without significant toxicity to most normal cells [28]. Direct introduction of the TRAIL gene into cancer cells elicited apoptosis and suppress tumor growth in vitro and in vitro. A notable advantage of TRAIL gene therapy is that TRAIL can kill nontransduced neighboring cancer cells through bystander effects. TRAIL may become a therapeutic agent for certain cancers. However, recent findings that normal human hepatocytes, brain tissue, and certain epithelial cells are susceptible to recombinant TRAIL proteins[29], and that nonselective expression of TRAIL gene in mice caused serious liver toxicity raised concerns about the potential toxicity of systemically administration of TRAIL. Targeting TRAIL gene expression to cancer cells by hTERT is expected to improve the safety of TRAIL gene therapy. Previous study showed that treatment of some lung and colon cancer cells with Ad/gTRAIL elicited strong antitumor activity in vitro and in vivo without toxic effects on primary human hepatocytes and in mice [25]. In breast cancer cells, Ad/gTRAIL was effective against cell lines resistant to doxorubicin and soluble TRAIL protein. Intralesional administration of Ad/gTRAIL effectively suppressed xenografted tumor growth resulted in long-term tumor-free survival in half of the mice [30]. This data suggests that Ad/gTRAIL has potential application in cancer therapy.

Meningiomas and gliomas are among the best candidates for intralesional treatment with gene based agents
[31]. In addition, malignant gliomas and meningiomas are predominantly telomerase positive, while normal brain tissues are telomerase negative. Kondo and his colleagues made a couple of plasmid constructs in which various caspases were put under the control of hTERT promoter and they used these constructs for in vitro and in vivo anti-glioma studies via liposome delivery system. They showed that hTERT/caspase constructs induced apoptosis in hTERT-positive malignant glioma cells but not in astrocytes or fibroblasts in vitro $[3,18]$. Moreover, these constructs significantly inhibited subcutaneously established meningioma and glioma tumors in nude mice by seven daily intratumoral injections. These studies provided the proof-of-principle evidence that hTERT promoter-driven suicide therapy may become a novel approach for the treatment of malignant meningiomas and gliomas. Although in vitro and in vivo results are encouraging, the potential use of these plasmid constructs in clinical settings is less promising. Compared with other vector system, especially adenovirus, the expression level mediated by liposome-DNA delivery is significantly lower when intratumoral injection is performed, whereas systemic treatment of malignant brain tumor by gene therapy may not be possible clinically.

Adenovirus is the most widely used vector in cancer gene therapy. Numerous clinical trials are based on adenoviral vector system $[32,33]$. We have made several adenoviral constructs using hTERT promoter to drive various apoptotic genes. Ad/gTRAIL is one of these constructs. In this study, we applied Ad/gTRAIL vector to glioma cells with varying malignancies. We found that the response of meningioma and glioma cells to Ad/gTRAIL treatment correlate with their malignancy level. Those with high malignancies are susceptible to Ad/gTRAIL treatment, while benign lower grade glioma cells and benign meningioma cells have very low hTERT expression and hence low GFP-TRAIL expression. Ad/gTRAIL may become an effective therapeutic agent for malignant brain tumors in cases where surgery is not an option and even as a prophylactic agent to prevent recurrence.

\section{Methods}

\section{Primary cell culture and cell lines}

Human tumor specimens were obtained and stored in accordance with the human subject research protocols approved by the institutional review board. The processing of tumor specimens has been described previously $[32,33]$. Briefly, after resection, a portion of each tumor was sent for routine histopathological analysis. The remainder of all samples was immediately used to establish primary cultures. Tumor fragments were dispersed into individual cells by treatment with Dispase 1 for 15 to $30 \mathrm{~min}$ at $37^{\circ} \mathrm{C}$. From each tumor, $1 \times 10^{6}$ cells were then plated in a $100 \mathrm{~mm}$ tissue culture dish in low-glucose 
Dulbecco's modified Eagle's medium (DMEM) with 10\% fetal bovine serum (FBS), and 1\% penicillin/streptomycin mixture. The cells were grown to confluence and then harvested, aliquoted, and stored in liquid nitrogen for future use. The U251, U87, U373, and SW1088 glioma cell lines were obtained from American Type Culture Collection (Manassas, VA). The NG-1 glioma cell line was a gift from Dr. TF Liu (University of Texas MD Anderson Cancer Center). U251, U87, U373, SW1088 and NG-1 glioma cell lines were grown in DMEM high glucose, L-glutamine medium with $10 \% \mathrm{FBS}$ and $1 \%$ penicillin/streptomycin mixture. All cells were cultured in a humidified atmosphere containing $5 \% \mathrm{CO}_{2}$ at $37^{\circ} \mathrm{C}$.

\section{Recombinant adenovirus vectors}

Ad/gTRAIL were constructed as described previously [34,35]. Ad/CMV-GFP was provided by Dr. T.J. Liu in our institution. Virus titers were determined by optical absorbance at A260 and by plaque assay. Particle/plaque ratios normally fell between 30:1 and 100:1. Based on a report by others on evaluation of the concentration [36], and our own experience, vector titers determined by A260 were used in this study while titers determined by plaque assays were used as additive information. Thus, the multiplicity of infection (MOI) of $1000 \mathrm{VPs}$ was equivalent to an MOI of 10-30 infectious units. Unless otherwise specified, $\mathrm{Ad} /$ CMV-GFP was used as the vector control, and PBS was used as a mock control. All viral preparations were free of contamination by $\mathrm{E}^{+}$adenovirus and endotoxin.

\section{Adenovirus infection}

For the infectivity analyses, human benign and malignant tumor cells $\left(5 \times 10^{5}\right)$ were infected with $1000 \mathrm{MOI} \mathrm{Ad} /$ g-TRAIL, 1000 MOI Ad/CMV-GFP, or PBS, in which Ad/g-TRAIL, Ad/CMV-GFP-infected cells express GFP. 72 hours after infection, the cells were treated with $0.05 \%$ trypsin for 5 minutes and washed twice with phosphatebuffered saline (PBS). The cells were then counted for GFP-positive cells by flow cytometry as described below, or visualized and photographed by using a Nikon Eclipse TE300 inverted fluorescence microscope (Nikon, Melville, NY) and were analyzed with MetaMorph imaging software (Universal Imaging Corp Downington, PA).

\section{Cell viability assay}

Human benign and malignant tumor cells were seeded in at a density of $3 \times 10^{3}$ cells/well in 96 well plates and allowed to grow for 20 hours at $37^{\circ} \mathrm{C}$. Cells were then infected with 1000 MOI Ad/g-TRAIL, 1000 MOI Ad/ CMV-GFP, or PBS at 7 days respectively. Cell viability was determined by 3-bis-[2-methoxy-4-nitro- 5 sulfenyl]- $2 \mathrm{H}$ tetrazolium-5-carboxanilide inner salt (XTT) assay (Cell Proliferation Kit II; Roche Molecular Biochemicals, Indianapolis, IN) following manafacturer's instructions. Each experiment was performed in quadruplicate and repeated at least three times.

\section{Real-time quantitative RT-PCR}

Total RNA was extracted using the Mini-prep RNeasy kit (Qiagen). cDNA synthesis was constructed from highgrade RNA from all samples using the High Capacity cDNA Reverse Transcription kit (Applied Biosystems, Foster City, CA, USA). Real-time Q PCR was performed in the ABI Prism 7700 Sequence Detection System according to the protocol of the manufacture. Typical amplification mixes $(25 \mu \mathrm{l})$ contained the sample DNA (or cDNA), 10x TaqMan Buffer $(2.5 \mu \mathrm{l}), 200 \mu \mathrm{m}$ dATP, dcP, dGTP, and $400 \mu \mathrm{M}$ dUTP, $5 \mathrm{mM} \mathrm{MgCl}$, 0.65 units of Ampli Taq Gold, 0.25 units of AmpErase uracil N-glycosyladse (UNG), $200 \mathrm{nM}$ each primer and $100 \mathrm{nM}$ probe. The thermal cycling conditions consist of 1 cycle at $2 \mathrm{~min}$ for $50^{\circ} \mathrm{C}$ and $10 \mathrm{~min}$ for $95^{\circ} \mathrm{C}$, and 50 cycles of $95^{\circ} \mathrm{C} 15 \mathrm{~s}$ and $60^{\circ} \mathrm{C}$ for $1 \mathrm{~min}$. All reactions were performed in duplicates. After the reaction, we used the built-in software in the 7700 system to perform analyses of the data and generate the standard curve, the $\mathrm{Ct}$ value of each testing sample and their corresponding starting quantity based on the relative standard curve.

\section{Western blot analysis}

The cells treated with 1000 MOI Ad/CMV-GFP or $1000 \mathrm{MOI} \mathrm{Ad} / \mathrm{g}$ TAIL at 3 days, the cell protein extraction was performed with Laemmli lysis buffer. Equal amounts of lysate were separated using 10\% SDS-PAGE and transferred to Hybond enhanced chemiluminescence membranes (Amersham, Piscataway, $\mathrm{NJ}$ ). The membranes were blocked with PBS-T containing $5 \%$ non-fat milk for $1 \mathrm{~h}$ or overnight at $4^{\circ} \mathrm{C}$, and incubated with primary antibodies for $1 \mathrm{~h}$ at room temperature. After washing three times with PBS containing $0.05 \%$ Tween, the membranes were incubated with peroxidase-conjugated secondary antibodies and developed using a chemiluminescence detection kit (ECL kit; Amersham).

\section{Fluorescence-activated cell sorting (FACS) and flow cytometric analysis}

Cells were seeded at $1 \times 10^{5} /$ well in 6 -well plates, and after an overnight incubation, cells were either treated with $1000 \mathrm{MOI}$ Ad/CMV-GFP or Ad/gTRAIL or complete media (control cells) for 24 hours. 72 hours later, both adherent and floating cells were harvested by trypsinization, washed with PBS, and fixed in $70 \%$ ethanol overnight at $4^{\circ} \mathrm{C}$. Before analysis, cells were stained with propidium iodide for $30 \mathrm{~min}$. The apoptosis induction was quantified by flow cytometric analysis. All experiments were performed in the Core Laboratory of the M. D. Anderson Cancer Center. 


\section{Intracranial xenografting of human meninglioma and glioma cells \\ Animals}

Protocol for animal use was approved by the Institutional Animal Care and Use Committee of Baylor College of Medicine, and was in accordance with National Institutes of Health guidelines (NIH publication number 85-23).

\section{Procedure}

A total of 24 female, 10 -weeks-old, $n u / n u$ athymic mice (Charles River Lab) were used. Human meningioma M6 and glioma U87 cell lines (at a concentration of $1 \times 10^{6}$ cells $/ 5 \mu \mathrm{L}$ ) were resuspended in PBS and injected into the right frontal lobe of nude mice using a guide-screw system implanted within the skull as described previous $[21,37,38]$. On day 3 , after the implantation of tumor cells, animals were divided into four groups, and the each group is treated with one single intratumoral injection $\left(1.5 \times 10^{8}\right.$ viral particles in $\left.5 \mu \mathrm{L}\right)$ with following: the first group animals $(n=6)$ were treated with Vectors Ad/CMV-GFP for meningioma M6; the second group animals $(n=6)$ were treated Vectors Ad/gTRAIL for meningioma M6; the third group animals $(n=6)$ were treated with Vectors Ad/CMV-GFP for glioma U87; the fourth group animals $(n=6)$ were treated with Ad/gTRAIL for glioma U87. Mice were anesthetized with xylazine/ketamine during the procedure. Mice showing general or local symptoms of toxicity were killed. When the animals became moribund due to tumor progression, they were euthanized and the brains were removed, fixed in $4 \%$ formaldehyde for $24 \mathrm{~h}$ at room temperature

\section{Histology and tumor analysis}

Brain tissue fixed for $24 \mathrm{~h}$ in $10 \%$ formalin solution, transferred to a $70 \%$ ethanol solution, and processed for paraffin embedding. Serial sections $(6 \mu \mathrm{m})$ were prepared and stained with H\&E according to standard histopathologic techniques. Stained sections were examined under light microscope ( $\times 100$ magnification).

\section{Apoptosis assay}

To detect apoptotic cells in tumor, we used an in situ cell death detection kit, POD (Roche Applied Science, Indianapolis, IN). The staining was performed according to the manufacturer's instructions, counterstained with haematoxylin, and viewed under a light microscope $(\times 400$ magnification). Brown staining indicates oligonucleosome cytoplasmic release resulting from apoptosis-induced DNA fragmentation. Counting was performed in randomly chosen fields, and the apoptosis was calculated as a percentage of at least 1,000 scored cells. Data analyzed with ImageJ software. Images segmented and the number of apoptotic cells quantified.
The standard fluorescein isothiocyanate-dependent apoptosis assay techniques (TUNEL or Annexin V) could not be used in this study because Ad/gTRAILinfected cells express GFP, which interferes with fluorescein isothiocyanate detection by means of flow cytometry.

\section{Statistical analysis}

Differences among the experimental groups were analyzed by analysis of variance (AOV) using statistical software (StatSoft, Tulsa, OK). A difference was considered statistically significant when the $P$ value was 0.05 or less. Differences in tumor growth in vivo among the treatment groups were assessed by AOV with a repeated measurement module. AOV was performed to determine statistical significance between each treatment group by using the SAS procedure with the SAS version 6.12 software. Survival was assessed by using the Kaplan-Meier method. Survival in different treatment groups was compared using the log-rank test.

\section{Abbreviations}

hTERT: Human telomerase reverse transcriptase; TRAlL: Tumor necrosis factor related apoptosis-inducing ligand; GFP: Green fluorescent protein; A/gTRAlL: Adenoviral vector with human telomerase reverse transcriptase promoter driven tumor necrosis factor related apoptosis-inducing ligand fusion gene; $\mathrm{Ad} / \mathrm{CMV}$ : Adenoviral vector with Cytomegalovirus promoter; FACS: Fluorescence-activated cell sorting; TUNEL: Terminal deoxynucleotidyl transferase- dUTP nick end labeling; dUTP: 2'-Deoxyuridine, 5'-Triphosphate; DR: death receptors; DISC: Death-inducing signaling complex Apo2L/TRAIL: (rhApo2L/TRAIL)- proapoptotic receptor agonist; DMEM: Dulbecco's modified Eagle's medium; FBS: Fetal bovine serum; XTT: 3-bis-[2-methoxy-4-nitro-5 sulfenyl]-2H-tetrazolium-5-carboxanilide inner salt; NG-1: neural glioma MOI-: Multiplicity Of Infection; SDS-PAGE:Sodium dodecyl sulfate polyacrylamide gel electrophoresis; PBS: phosphate-buffered saline; UNG: Uracil Nglycosyladse RT Q-PCR: Real-time quantitative polymerase chain reaction; AOV: Analysis of variance

\section{Acknowledgements}

The authors thanks for Chandra Somasundaram, Weijun Xiong, and Jianfeng Liang for technical assistance and with the preparation of this manuscript. Financial support was provided by the National Institute of Cancer grant (R01 CA 098582-01A1 B. Fang). This work was also supported in part by Texas Nerve and Paralysis Institute.

\section{Author details}

${ }^{1}$ Department of Neurosurgery, The University of Texas Medical School at Houston, 6400 Fannin Street, Houston, TX 77030, USA. ${ }^{2}$ Department of Thoracic and Cardiovascular Surgery, The University of Texas M. D. Anderson Cancer Center, Houston, Texas 77030, USA. ${ }^{3}$ Department of Neurosurgery, The University of Texas M. D. Anderson Cancer Center, Houston, Texas 77030, USA. ${ }^{4}$ Texas Nerve and Paralysis Institute, 6400. Fannin St., Houston, Texas 77030, USA. ${ }^{5}$ Department of Biochemistry and Molecular Biology, The George Washington University Medical Center, 2300 I Street, NW, Washington, DC 20037, USA.

\section{Authors' contributions}

$J \mathrm{~L}, \mathrm{IM}$ and BF designed the study. $J$ draft of the manuscript, $J \mathrm{~L}, \mathrm{AZ}$, performed experiments, WA, BF, participated in manuscript correction and Performed data analysis, KB RN, DK, FM, IM revised the manuscript. All authors read and approved the final manuscript.

\section{Competing interests}

The authors declare that they have no competing interests. 
Received: 30 June 2011 Accepted: 28 October 2011

Published: 28 October 2011

\section{References}

1. Hoffman S, Propp JM, McCarthy BJ: Temporal trends in incidence of primary brain tumors in the United States, 1985-1999. Neuro Oncol 2006, 8(1):27-37

2. Wrensch M, Minn Y, Chew T, Bondy M, Berger MS: Epidemiology of primary brain tumors: current concepts and review of the literature. Neuro Oncol 2002, 4(4):278-299.

3. Komata $T$, Kondo $Y$, Kanzawa $T$, Ito H, Hirohata $S$, Koga $S$, Sumiyoshi H, Takakura M, Inoue M, Barna BP: Caspase- 8 gene therapy using the human telomerase reverse transcriptase promoter for malignant glioma cells. Hum Gene Ther 2002, 13(9):1015-1025.

4. Dash R, Azab B, Shen XN, Sokhi UK, Sarkar S, Su ZZ, Wang XY, Claudio PP, Dent $P$, Dmitriev IP: Developing an effective gene therapy for prostate cancer: New technologies with potential to translate from the laboratory into the clinic. Discov Med 2011, 11(56):46-56.

5. Kroeger KM, Muhammad AK, Baker GJ, Assi H, Wibowo MK, Xiong W, Yagiz K, Candolfi M, Lowenstein PR, Castro MG: Gene therapy and virotherapy: novel therapeutic approaches for brain tumors. Discov Med 2010, 10(53):293-304

6. Hogg RT, Thorpe P, Gerard RD: Retargeting adenoviral vectors to improve gene transfer into tumors. Cancer Gene Ther 2011, 18(4):275-287.

7. Kim NW, Piatyszek MA, Prowse KR, Harley CB, West MD, Ho PL, Coviello GM, Wright WE, Weinrich SL, Shay JW: Specific association of human telomerase activity with immortal cells and cancer. Science 1994, 266(5193):2011-2015.

8. Onimaru M, Ohuchida K, Nagai E, Mizumoto K, Egami T, Cui L, Sato N, Uchino J, Takayama K, Hashizume M: Combination with low-dose gemcitabine and hTERT-promoter-dependent conditionally replicative adenovirus enhances cytotoxicity through their crosstalk mechanisms in pancreatic cancer. Cancer Lett 2010, 294(2):178-186.

9. Onimaru M, Ohuchida K, Mizumoto K, Nagai E, Cui L, Toma H, Takayama K, Matsumoto K, Hashizume M, Tanaka M: hTERT-promoter-dependent oncolytic adenovirus enhances the transduction and therapeutic efficacy of replication-defective adenovirus vectors in pancreatic cancer cells. Cancer Sci 2010, 101(3):735-742

10. Griffith TS, Anderson RD, Davidson BL, Williams RD, Ratliff TL: Adenoviralmediated transfer of the TNF-related apoptosis-inducing ligand/Apo-2 ligand gene induces tumor cell apoptosis. J Immunol 2000, 165(5):2886-2894.

11. Harley $C B$, Futcher $A B$, Greider $C W$ : Telomeres shorten during ageing of human fibroblasts. Nature 1990, 345(6274):458-460.

12. Gu J, Andreeff M, Roth JA, Fang B: hTERT promoter induces tumorspecific Bax gene expression and cell killing in syngenic mouse tumor model and prevents systemic toxicity. Gene Ther 2002, 9(1):30-37.

13. Bhardwaj A, Aggarwal BB: Receptor-mediated choreography of life and death. J Clin Immunol 2003, 23(5):317-332.

14. Counter CM, Meyerson M, Eaton EN, Weinberg RA: The catalytic subunit of yeast telomerase. Proc Natl Acad Sci USA 1997, 94(17):9202-9207.

15. Griffith TS, Broghammer EL: Suppression of tumor growth following intralesional therapy with TRAIL recombinant adenovirus. Mol Ther 2001, 4(3):257-266

16. Ashkenazi A, Herbst RS: To kill a tumor cell: the potential of proapoptotic receptor agonists. J Clin Invest 2008, 118(6):1979-1990.

17. Counter CM, Meyerson M, Eaton EN, Ellisen LW, Caddle SD, Haber DA, Weinberg RA: Telomerase activity is restored in human cells by ectopic expression of hTERT (hEST2), the catalytic subunit of telomerase. Oncogene 1998, 16(9):1217-1222.

18. Komata T, Kondo Y, Kanzawa T, Hirohata S, Koga S, Sumiyoshi H, Srinivasula SM, Barna BP, Germano IM, Takakura M: Treatment of malignant glioma cells with the transfer of constitutively active caspase- 6 using the human telomerase catalytic subunit (human telomerase reverse transcriptase) gene promoter. Cancer Res 2001, 61(15):5796-5802.

19. Kilian A, Bowtell DD, Abud HE, Hime GR, Venter DJ, Keese PK, Duncan EL, Reddel RR, Jefferson RA: Isolation of a candidate human telomerase catalytic subunit gene, which reveals complex splicing patterns in different cell types. Hum Mol Genet 1997, 6(12):2011-2019.
20. Allshire RC, Dempster M, Hastie ND: Human telomeres contain at least three types of G-rich repeat distributed non-randomly. Nucleic Acids Res 1989, 17(12):4611-4627.

21. Fang $B, J i L$, Bouvet $M$, Roth JA: Evaluation of GAL4/TATA in vivo. Induction of transgene expression by adenovirally mediated gene codelivery. J Biol Chem 1998, 273(9):4972-4975.

22. Kagawa S, He C, Gu J, Koch P, Rha SJ, Roth JA, Curley SA, Stephens LC, Fang B: Antitumor activity and bystander effects of the tumor necrosis factor-related apoptosis-inducing ligand (TRAIL) gene. Cancer Res 2001, 61(8):3330-3338

23. Huang $X$, Lin T, Gu J, Zhang L, Roth JA, Liu J, Fang B: Cell to cell contact required for bystander effect of the TNF-related apoptosis-inducing ligand (TRAIL) gene. Int J Oncol 2003, 22(6):1241-1245.

24. Gu J, Kagawa S, Takakura M, Kyo S, Inoue M, Roth JA, Fang B: Tumorspecific transgene expression from the human telomerase reverse transcriptase promoter enables targeting of the therapeutic effects of the Bax gene to cancers. Cancer Res 2000, 60(19):5359-5364.

25. Lin T, Gu J, Zhang L, Huang X, Stephens LC, Curley SA, Fang B: Targeted expression of green fluorescent protein/tumor necrosis factor-related apoptosis-inducing ligand fusion protein from human telomerase reverse transcriptase promoter elicits antitumor activity without toxic effects on primary human hepatocytes. Cancer Res 2002, 62(13):3620-3625.

26. Koch PE, Guo ZS, Kagawa S, Gu J, Roth JA, Fang B: Augmenting transgene expression from carcinoembryonic antigen (CEA) promoter via a GAL4 gene regulatory system. Mol Ther 2001, 3(3):278-283.

27. Gu J, Fang B: Telomerase promoter-driven cancer gene therapy. Cancer Biol Ther 2003, 2(4 Suppl 1):S64-70.

28. Li YM, Song ST, Jiang ZF, Zhang Q, Su CQ, Liao GQ, Qu YM, Xie GQ, Li MY Ge FJ: Telomerase-specific oncolytic virotherapy for human hepatocellular carcinoma. World J Gastroenterol 2008, 14(8):1274-1279.

29. Jo M, Kim TH, Seol DW, Esplen JE, Dorko K, Billiar TR, Strom SC: Apoptosis induced in normal human hepatocytes by tumor necrosis factor-related apoptosis-inducing ligand. Nat Med 2000, 6(5):564-567.

30. Lin T, Huang $X$, Gu J, Zhang L, Roth JA, Xiong M, Curley SA, Yu Y, Hunt KK, Fang B: Long-term tumor-free survival from treatment with the GFPTRAIL fusion gene expressed from the hTERT promoter in breast cancer cells. Oncogene 2002, 21(52):8020-8028.

31. Candolfi M, Pluhar GE, Kroeger K, Puntel M, Curtin J, Barcia C, Muhammad AK, Xiong W, Liu C, Mondkar S: Optimization of adenoviral vector-mediated transgene expression in the canine brain in vivo, and in canine glioma cells in vitro. Neuro Oncol 2007, 9(3):245-258.

32. Yu de B, Zhong SY, Yang M, Wang YG, Qian QJ, Zheng S, Liu XY: Potent antitumor activity of double-regulated oncolytic adenovirus-mediated ST13 for colorectal cancer. Cancer Sci 2009, 100(4):678-683.

33. Hogg RT, Garcia JA, Gerard RD: Adenoviral targeting of gene expression to tumors. Cancer Gene Ther 2010, 17(6):375-386.

34. Blackburn EH: Structure and function of telomeres. Nature 1991, 350(6319):569-573

35. Chen B, He C, Lao WF, Huang XF, Fang BL: [Activity of the TNF-related apoptosis-inducing ligand gene expressed from the hTERT promoter on colon cancer cell line HT-29]. Zhejiang Da Xue Xue Bao Yi Xue Ban 2006, 35(1):45-49.

36. Mittereder N, March KL, Trapnell BC: Evaluation of the concentration and bioactivity of adenovirus vectors for gene therapy. J Virol 1996, 70(11):7498-7509.

37. Feng J, Funk WD, Wang SS, Weinrich SL, Avilion AA, Chiu CP, Adams RR, Chang E, Allsopp RC, Yu J: The RNA component of human telomerase. Science 1995, 269(5228):1236-1241.

38. McCutcheon IE, Friend KE, Gerdes TM, Zhang BM, Wildrick DM, Fuller GN: Intracranial injection of human meningioma cells in athymic mice: an orthotopic model for meningioma growth. J Neurosurg 2000, 92(2):306-314

doi:10.1186/1475-2867-11-35

Cite this article as: Li et al:: Targeting different types of human meningioma and glioma cells using a novel adenoviral vector expressing GFP-TRAIL fusion protein from hTERT promoter. Cancer Cell International 2011 11:35. 